\title{
Communication in virtual supply chain teams
}

\author{
J. Carletta, R. McEwan, and A. Anderson \\ Universities of Edinburgh and Glasgow
}

Human Communication Research Centre, 2 Buccleuch Place

Edinburgh EH8 9LW Scotland

Phone: +44 (0)131 650-4438

Fax: $\quad+44(0) 131650-4587$

Email: J.Carletta@edinburgh.ac.uk

\begin{abstract}
As manufacturers require closer and closer links to geographically more diverse suppliers in order remain competitive, virtual teamworking is beginning to look attractive. However, the full benefits which closer communication are meant to bring require informal and free interaction among team members in a way which communications technology could block. We use case studies of two supply chain teams trying desktop conferencing technology for collaborative work to recommend how best to introduce virtual teamworking.
\end{abstract}

\section{Keywords}

virtual teamworking, supply chain partnerships, technological innovation

\section{INTRODUCTION}

The globalization of the marketplace has increased competition and made it necessary for manufacturers to develop new products and cheaper production processes quickly. This places pressure on the supply chain. Traditionally, an original equipment manufacturer (OEM) has simply faxed specifications for parts to a range of potential suppliers and accepted the lowest bid (Jackson, 1985). Such techniques work in an environment where the market is certain and competition among suppliers is high (Gattorna and Walters, 1996), but in rapidly changing business environments, longer term partnerships between companies can have the advantage of allowing the kind of free access to information and co-operation on design. This in turn will lead to increased competitiveness by promoting changes in design or in production processes which improve the value for money of the final product (Carlisle and Parker, 1989). Supply chain partnerships effectively 
institute cross-company teamworking, in which the two companies involved work out shared goals which will benefit everyone involved.

Although in theory partnerships are a good idea, they can be difficult to implement. Just as companies think that they have implemented teamworking when they still have hierarchically structured workgroups (Guzzo and Dickson, 1996), OEMs often believe they have established partnerships but still dominate their suppliers (Greek, 1997). One of the major obstacles to true partnership is that it requires close collaboration and frequent, informal meetings. The costs in terms of additional travel time are often unacceptable and can lead to the same delays which partnership is meant to solve. Virtual teamworking, which at its simplest involves electronic document transfer or email, but can also involve audio and videoconferencing, has been used successfully in a variety of organisational settings (Lipnack and Stamps, 1997). Virtual teamworking has also been reported as very successful at increasing collaboration among the sites of a major international company (Prokesch, 1997). Remote communication with video, audio, and a shared editor has been shown to be as effective as face-to-face communication for a laboratory design task (Olson et al., 1995). (Martin, 1997) reports that using the internet for virtual teamworking between a tool designer and manufacturer performing concurrent engineering can reduce overheads and manufacturing lead times. As a result, virtual teamworking is seen as one possible way of making supply chain partnerships work. However, using communication technology affects the course of a meeting. Even the very best video links do not allow as clear communication as face-to-face interaction (Anderson et al., 1996, Doherty-Sneddon et al., 1997) and tend to place a psychological distance between the users (Sellen, 1995), resulting in more formal interaction. Using two case studies, we address the question of how using communication technology affects partnerships, and give recommendations for the introduction of virtual teamworking which will help participants benefit fully from the technology.

\section{HOW THE BENEFITS OF PARTNERSHIP ARISE}

In a partnership, the supply chain team has shared, group goals; such goals have been show to improve group performance by increasing individual effort, planning, and co-operation among group members (Weldon and Weingart, 1993). In situations like the ones manufacturers now face, where co-operation will decrease delays, this effect can be useful in its own right. However, one of the main benefits of starting supply chain partnerships is not just to facilitate the exchange of information or to make the team cohesive enough that they are willing to help each other, but to promote the sort of collaboration which leads to technological innovation. The goal of automotive manufacturers is to sell products, and that means offering better value for money than one's competitors. It doesn't work to simply offer the same products for the same prices, if one's competition is continuously improving. Technological innovation allows OEMs both to develop cheaper manufacturing processes for their current products and to design new and more valuable products. Since OEMs can not be expected to 
understand all of the technical issues which affect the design of supplied parts, they must work closely with their suppliers if they are to maximize value for money.

Communication is closely related to technological innovation. Individual companies innovate most if they have "flatter, less hierarchical structures" and encourage "direct and frequent communication between all levels and sectors of the business" (1991 p. 4). Burns and Stalker (1966) suggested that the faster the rate of change in the external environment, the more problems and opportunities will arise which cannot easily be addressed from within the existing management structure. Since it is never certain from which pair or group of functions within an organization the next breakthrough will arise, innovation requires flexible crossfunctional communication and consultative communication between people of different ranks, not just order-passing. In meetings, issues of authority are crucial to whether or not this communication will occur. Carletta et al. (under revision), in a study of single-company cross-functional problem-solving teams from small-tomedium-sized manufacturing firms, showed that those which place authority in the group as a whole show much more flexible communication patterns than those which retain an individual group manager who is responsible for making final decisions, mostly because the group manager tends to monopolize the floor, speaking more than anyone else, participating in more pairwise conversations, and initiating more of the interaction than anyone else. The key reason for the group manager's behaviour is that having authority for decision-making placed in him raises his status within the team. In any group, participants who are accorded a higher status in relation to the task at hand have been shown to dominate proceedings in this way (Berger et al., 1980). Low status members often do not offer and are not asked to give information which only they have, even if it is crucial to the task. Low status participants are also extremely unlikely to express their ideas in front of the group (Silver et al., 1994). Thus one key to technological innovation is for companies to establish joint authority teams rather than traditionally-structured ones.

Although these studies have been done on individual companies, the same argument applies for teams drawn from across the supply chain --- concentration of authority in one or two people in the team (in this case, usually those from the OEM) will raise their status in a way which may block technological innovations from arising, by leading them to dominate meetings and hindering free interaction. Historically, however, supply chain relations have been even more status-driven and competitive than those in individual companies, especially in Britain (Carlisle and Parker, 1989). If such people can't see the need to cooperate, then they will not see the need to change to level the status differences which block the interaction from which technological innovation arises. Of course, such a radical restructuring of corporate relationships requires institutional support for the change, and this no communication technology can supply. However, for companies which are committed to establishing or maintaining a partnership, understand that this means sharing authority, and need to keep in close communication, an important question is how using communication technology is likely to affect_interaction between the companies. 


\section{THE STUDY}

For this study, we observed two supply chain teams. These teams were from the same section within an OEM, but were working on separate projects. The OEM, in conjunction with their suppliers, were taking part in virtual teamworking trials as part of TEAM*, a European Union project. The management of the OEM clearly believed that partnerships were of benefit for their own commercial situation. Our main source of information for this study is audio recordings of team meetings. We also asked team members to fill out questionnaires about their experience with IT and with face-to-face teamworking and interviewed most team members to obtain deeper comments about the same general issues and about the company's attitude towards teamworking and supply chain partnership. Before using the technology, both teams received one and a half days of technology training organised by workers on the TEAM project. In addition, one team took part in a half day workshop in which they discussed what expectations they had for the technology and what kinds of benefits it might bring. This information is used to corroborate our observations about the meetings, show where subjective perceptions differ from what we observed during actual team meetings, and shed further light on where the pressures for virtual teamworking arise for these teams.

\subsection{The technology}

The meetings on which our observations are based were conducted using TEAM technology. This provides computer support for collaborative working, including video-conferencing, shared whiteboard, shared $C A D$ applications, and shared webbased product libraries. The interface controls themselves were largely point-andclick. Both teams used the technology to solve a problem with an existing design which originated with the OEM. In both cases, the OEM had the equipment situated in the middle of a busy open plan office which had no partitions. One supplier sited the equipment in a vacant room and the other in a partitioned area which formed part of an open plan.

\subsection{The teams}

For Case Study A, the team had one meeting which lasted an hour and a half. In this team, the supplier was a large, international company. They had a long-term relationship with the OEM and were keen to be involved in any IT initiatives originating from them. The OEM was their biggest customer. The OEM stated that the participants from the two companies got on well, with a very close working relationship. The purpose of the meeting was to settle a design detail for a part being manufactured by the supplier; the detail had to do with the angle at

\footnotetext{
* «Team Based European Automotive Manufacture", project AC070 sponsored by the European Commission ACTS Programme, DGXIII.. The present authors had no involvement in TEAM.
} 
which one subassembly should be mounted on the frame of the part. The OEM wished to have the subassembly mounted at an angle which would increase the supplier's manufacturing costs because that angle would definitely keep the part clear of other working parts outside of this supplier's knowledge; the supplier wished to know whether any of the cheaper assembly options would work. Information originating from both companies was necessary to work out the ramifications of the other options. The primary participants in the meeting were a chassis engineer from the OEM dedicated to the project of which this component discussion was a part, and two staff from the supplier --- a designer, whose main work was using CAD tools and who had been trained on the communication technology, and a design engineer, who was also working on the project at a more senior level. This design engineer had never seen the technology before and attended the meeting to see it in action. A member of the TEAM project was present at the OEM's site; he operated the software at their end. There were also several on-lookers present at the OEM's site --- an OEM design engineer from the team in Case Study B who wished to see how the technology worked, the project manager in charge of the OEM's involvement with the TEAM project, and one of the authors, who was present to set up the recording equipment.

In Case Study B, the team had three short meetings which were primarily between two design engineers at the OEM and a CAD engineer at the supplier, a small local company. The relationship with the OEM was less well-established both because the engineers at both companies were recent recruits and because the supplier was under new management. Relations were amicable. At any one meeting, one of the OEM engineers took a more central role, with his colleague participating as needed. A product manager from the supplier participated in one of the meetings in order to arrange production volumes and delivery schedules. The primary purpose of the meetings was to discuss changes to the supplier's existing design which would be necessary for a new OEM assembly. The OEM's concern was that the design modification proposed by the supplier was fit for the purpose, and the modifications were discussed in detail. In the course of the discussion, other issues became apparent. These included assigning and locating part numbers, and volumes and schedules required by both parties for prototype testing. The CAD engineer at the supplier had been trained to use the communications technology and one of the OEM design engineers had observed the meeting from Case Study A. A technology expert was present at the OEM and was consulted on an ad hoc basis, for instance, for dealing with difficulties in audio transmissions, to help locate hidden screens, and to save information.

In questionnaires completed by five team members, all reported that they worked as part of one or more teams daily and had experience of working in crosscompany and multi-disciplinary teams. Exchange of information between these teams was mainly via formal and informal face to face meetings, telephone, fax and conventional mail. Email, electronic document exchange and audio/video conferencing was reported as being rarely or never used by four out of the five respondents. All members also reported using computers in their job, and four out of five of them spent most of their working day using them. The one engineer who reported spending «very little time» on a computer each day was one of the design 
engineers from the OEM. All but the supplier's CAD engineer in Case Study B reported being accustomed to software with point and click interfaces.

\section{OBSERVATIONS}

One way of measuring how well a virtual team functions is to analyse how they communicate and to suggest how this communication differs from how the teams would behave if they were operating face-to-face. To perform this analysis, we prepared careful transcriptions of the team meetings from tape recordings and considered both who talked to whom and what kinds of things were said. We first noted whether an utterance was addressed over the communication link or was aimed solely at the other participants at the same site. We then classified the utterances according to whether they directly addressed the task, concerned an information source (such as a CAD diagram) which would be useful for completing the task, were purely social, were about how to use the technology, or resulted from some kind of external distraction which was not part of the meeting. We also identified utterances which the speaker intended as questions and coded utterances as being «task area» or «socioemotional» in the terms of Interaction Process Analysis (Bales, 1951); the proportion of «task area» utterances effectively measures how much an individual is directing the proceedings. Of course, in any data set this small, especially one without a face-to-face comparison, such classifications can only be considered illustrative, but they provide more objective evidence about interaction in the team than can be obtained by simply describing what happened in the meetings.

\subsection{Sociality and informal interaction}

One of the benefits of virtual teamworking is meant to be better informal communication between the companies, of the sort that face-to-face meetings naturally encourage. In the alignment workshop of Case Study B, participants from both companies said that meetings among the core team members were becoming more common, and they agreed that virtual teamworking would help promote a good relationship between the companies, since if they didn't need to travel team members would have time to communicate meaningfully with each other instead of just managing to complete the paperwork involved with a project. 'Small talk' itself is important as part of building a long-term relationship (Gutek, 1997), and so the technology should allow small talk to occur. (Boden and Molotch, 1994) claimed that any kind of communication technology socially distances the participants, so that small talk is less likely to occur. In addition, one of the real benefits of face-to-face meetings is that one can corner individuals or small groups of people either beforehand or afterwards and raise topics which may be important to one's work, but which are too peripheral or not of general enough interest to raise in the meeting itself (Boden, 1994). In some cases, people only suffer through meetings for these opportunities. If a partnership is to be maintained, the technology should allow participants to raise topics informally and without extensive advance preparation in the same way that face-to-face meetings allow. 
Although it is difficult for outsiders to assess what discussions are central to a technical meeting and what are peripheral, a related phenomenon is the presence of small talk. Teams which are comfortable enough to raise peripheral issues with each other will also engage in some purely social talk. In Case Study A's interviews, the supplier stressed that a good social relationship with the OEM was necessary as a prerequisite to being able to cooperate well, and the OEM said that the team got on well socially face-to-face. However, we found that our teams spent very little time on small talk --- at least when it came to talking to each other. In Case Study A, $44 \%$ of turns in local conversations at the OEM were purely social, but only $8 \%$ of cross-site turns --- and apart from a few jokes stemming from problems using the interface --- that was entirely with the TEAM technology expert while the main OEM participant was away. Case Study B's meetings always contained roughly $10 \%$ purely social utterances between the main participants across the interface. The supplier said that this was very similar to their face-to-face meetings, although they gave the impression that they would like a more social relationship. Although lack of small talk is probably due partly to the corporate relationships, it is likely that the communication technology made it harder to establish a social relationship. In Case Study A, the supplier tried but failed to establish social conversations in a meeting gap; in a face-to-face meeting, it would have been rude to ignore this attempt, and in fact, gaps ought to spawn such conversations since it is awkward to sit silently in a meeting room, at least when working face-to-face. The OEM of Case Study A tried to maintain contact early on during delays due to lack of information, but soon lapsed into side conversations; presumably the quality of the video information was not high enough to make informal contact easy. For logistical reasons, it is useful to have communication technology sited where the team members actually work, but if this is an open plan office (as it was for the OEM), this can also lead to a high rate or external disturbances which cause further meeting gaps. During the meeting of Case Study A, the OEM took four phone calls and several incoming faxes, and there was much confusion when other phones in the open plan rang. This level of distraction would be considered rude in a face-to-face meeting among equals, although admittedly some participants actively encourage it to make others think they are important. Failure to attend is considered to show a lack of commitment in face-to-face discussions (Boden and Molotch, 1994) and may harm partnership even if the failure is completely unintentional. External disturbances are not inevitable if the technology is sited in open plan offices --- there were very few in the meetings of Case Study B, even though exactly the same equipment was used -- but they are a potential hazard of the technology.

The immediacy of communication using the interface did bring one unexpected advantage to the supplier for Case Study A --- the OEM responded to a concern in a day which ordinarily would have taken a fortnight of phone calls and faxes, even though the response only directly benefited the supplier. As one progresses from faxes through telephones to face-to-face meetings, the interaction becomes more difficult to set up, but perceived commitment to complete actions resulting from the interaction is higher. Evidently despite the psychological distance which the interface imposes (Sellen, 1995), virtual meetings can still be placed somewhere between telephones and face-to-face meetings in terms of the commitment that 
ensues. However, as with other technologies, this immediacy is not always a benefit and may decrease as virtual teamworking becomes less novel.

\subsection{Control of the proceedings}

There are three distinct possible factors affecting who had control of the proceedings in these meetings which should be taken into account when introducing virtual teamworking: facility with the technology and access to technological expertise, the corporate relationship, and status differences among the team members.

In Case Study A, the meeting was about a question which arose from the supplier, and naturally one would have expected them to have some degree of control over the proceedings. However, the OEM was not entirely prepared to answer the supplier's question because they did not have the clearest information sources available. The supplier came up with a reasonable work-around for the meeting's difficulties --- training the video-camera on relevant but not ideal hardcopy diagrams instead of on their faces --- but because there was a hope of an even better information source arising from the OEM, their suggestion was ignored, even though this led to lengthy delays. Since the delays clearly arose from the OEM, this made it much easier for the OEM than for the supplier to establish contact again after gaps in the meeting. This put the supplier at a disadvantage; at several points they seemed unclear whether the OEM even understood the question which they wished to have addressed but couldn't initiate a conversation which would clear up the confusion. After the first cross-site contact, there were eight lengthy gaps, seven of which were ended by the OEM. The supplier only even attempted to end a gap twice despite the fact that the impetus for the meeting came from them. Having large gaps in the meeting due to delays in loading information is bound to cause the relationship to be more strained, even if this is not deliberate. For instance, the supplier's design engineer became very formal in the way he asked for essential information by the end of the meeting. There is probably always some tension of this sort even in face-to-face supply chain teams, since it is very difficult to share information well across companies. However, in this case, the situation was exacerbated by the technology, and especially by the fact that the technology expert was present at the OEM, giving them extra control over what information sources were used.

Traditional corporate relationships also probably influenced control in these meetings. Although the technology had roughly symmetrical control for the two sites, even in Case Study B the supplier had difficulty exercising it. In the first meeting, the supplier began by typing in to the whiteboard, but ended up dictating information to the OEM instead because the OEM ignored anything they didn't type themselves. The supplier were clearly keen to have a joint public record of decisions, although the OEM were just as happy to scribble decisions on a scrap of paper. Although the supplier was perfectly capable of using the interface, again, having the technology expert present at the OEM made it difficult for them to act against the OEM's wishes, and the OEM clearly wasn't happy with them entering information. For partnership, since both parties' goals should be addressed, it's 
important that the meetings have public, negotiated agendas, notes, and records of decisions taken which both parties can alter. Even for non-partnerships, having public records allows teams to reflect on their decision processes and to make themselves more effective (West, 1996).

Introducing virtual teamworking can bring together groups with larger status disparities than are usual in face-to-face meetings simply because of who is familiar with the virtual technology. In Case Study A, the supplier design engineer was much closer in status and function to the OEM project manager, to whom (as was said during the interviews) the CAD designer wouldn't ordinarily speak even though he appeared to have the better command of the technical information needed for the discussion held. During gaps in the meeting, the supplier participants rehearsed technical aspects of the problem; $41 \%$ of utterances during local conversations at the supplier were about the task, with the design engineer and CAD designer taking nearly equal roles in those conversations, both in terms of who asked the questions and who directed the interaction, using Bales' distinctions. When they were talking to the OEM, the two participants from the supplier again took roughly equivalent roles when it came to talking about the task or information sources relevant to the task. This is unusual given that participants from both sites commented on the large status disparity during the interviews; usually low status individuals take a much less dominant role (Berger et al., 1980). The technology itself could be facilitating this change from usual behaviour. The CAD designer knew how to use the equipment and the supplier's design engineer did not. Training low status group members in some skill relevant to the group's task has been shown to raise their effective status in the group, leading them to participate more fully (Berger et al., 1980). In addition, the person most familiar with the technology is also most likely to operate it, putting them in some degree of control of the proceedings and making them more likely to be called into crosssite conversations. In Stalker's model of how technological innovation arises, this is a positive advantage to using the technology, as long as low status team members are given better technology training than their high status counterparts.

\section{RECOMMENDATIONS}

Reflecting on the way virtual teams communicate is useful for understanding the effects of the technology on group interaction. As we have demonstrated, although virtual teamworking has many potential advantages for supply chain teams, it also has several potential drawbacks in terms of maintaining the differences in participation which arise from the history of status differences in supply chain teams but which may block the technological innovation which partnerships are meant to promote. To benefit fully from virtual teamworking, we recommend that supply chain teams use the following techniques:

Technological facilitation. Given more familiarity with the software, some of the inefficiencies which lead to irritation and potentially to a worse relationship would not have occurred. However, members of both teams were reluctant to spend the time in training since they prefer learning "on the job", especially since, as with any new technology, they were unsure that it would continue to be 
supported. One untrained participant who was used to point-and-click interfaces and had seen the interface used once before said that he didn't think his lack of training made any difference. The interface was deceptively simple unless things went wrong. Many industries already use trained facilitators for face-to-face teams in order to encourage them to operate co-operatively rather than falling into old habits governed by status and hierarchies, sometimes by training some of their existing employees to act in this capacity and sometimes by hiring a dedicated person for it. Therefore we advocate introducing a virtual team facilitator whose job it is to liaise with people setting up a virtual team to enable them to do the necessary data preparation, and to attend virtual team meetings in order to run the interface. Although this may seem an unacceptable cost, one of the best ways to learn computer skills is by watching someone else perform them. As each team develops, the knowledge will be transferred to team members, and the facilitator can move on to help the next team. The particular difficulties for current CADbased team members who have no experience of point-and-click interfaces should be kept in mind. To overcome some of the cross-company status difficulties, the technological facilitator should be present at the supplier's site rather than the OEM's whenever possible.

Limited initial training. Despite the advantages of technological facilitation, we feel that it is still useful to have some limited initial training for team members, not on how to use the technology, but primarily to explain the benefits and costs of using it. For instance, we suggest explicitly suggesting to team members that virtual meetings can more easily be set up, postponed and reconvened than face-toface ones, and that maintaining a social relationship and allowing off-topic talk is difficult, so that they must work at it. Stressing the benefits of the technology should help acceptance, although there is evidence that people determine their attitudes towards new technology by reference to their peer groups, not their trainers or their teams (Burkhardt, 1994). This suggests that companies should be sure that not to miss out participants from any of the relevant functions. We also suggest that teams explicitly be told about good meeting practice for consensual groups, such as setting mutually agreed goals, laying out an agenda at the beginning of the meeting, and making sure actions are specific enough to be carried out (Doyle and Straus, 1976). This kind of information should be reinforced by the facilitator.

Joint agenda setting and decision recording. The technology could do more to encourage good meeting practice by designating agenda and decision pages to a whiteboard application and bringing them up when the technology is started up, rather than allowing teams to come up with their own styles of working. Much of the role of a trained facilitator in a face-to-face meeting is to negotiate a mutually agreeable agenda and to make sure decisions are well-specified, agreed, and recorded. The technology can not force a team to allow both companies to contribute to the team's goals and decision-making, but it can at least remind them that it is important to make these things clear, which is important even for meetings where the companies are not equal partners.

Equal access for each person. Some of the difficulties in participation arose out of the privileged access for the person who was sitting at the keyboard at each site. This would be more important in teams which represented more equal partnerships 
than they were in the ones we studied. The easiest way to do this would be to use desktop conferencing software which is installed on everyone's desktop machine. This would have the benefit of allowing some participants to talk informally whenever one was trying to load information into an application; even in teams that are familiar with the technology, there will be gaps of this nature, and if all the participants at one site are gathered around one machine with the keyboard occupied that makes it difficult to talk to the other site about anything but the delay. It will also allow people to establish short, informal meetings with parts of the team as needed, compensating somewhat for the inability to «bump into» people after meetings and in the coffee room. Unfortunately, assuming desktop siting of the technology causes problems for current CAD-based participants, who tend not to have easy access to any desktop machines. Another potential problem is that people can be reluctant to use the technology unless they are seen to be in a meeting, since people in meetings are considered «busier» and more important than people who simply work at their desks. In addition, people working at their desks are liable to face external distractions which harm the team relationships. To correct for this, one might hang «Do Not Disturb» signs which, if the true reasons are too awkward, can always be put down to background noise making it difficult for the participants to hear each other.

Some face-to-face meetings. Virtual teams should expect that they will not be able to maintain good social relationships as well as they would be able to face-toface, and therefore should consider meeting face-to-face occasionally to make up the deficit, especially at the beginning of a team.

\section{REFERENCES}

(1991) Innovation in Manufacturing Industry: Volume I (Report), House of Lords Select Committee on Science and Technology, 1990-1991 Session, London.

Anderson, A. H., Newlands, A., Mullin, J., Fleming, A. M., Doherty-Sneddon, G. and Van der Velden, J. (1996) Impact of video-mediated communication on simulated service encounters. Interacting with Computers, 8, 193-206.

Bales, R. F. (1951) Interaction Process Analysis: A method for the study of small groups. Addison-Wesley, Cambridge, MA.

Berger, J., Rosenholtz, S. J. and Zelditch Jr, M. (1980) Status organizing processes. Annual Review of Sociology, 6, 479-508.

Boden, D. (1994) The Business of Talk: Organizations in Action. Blackwell, Oxford, England.

Boden, D. and Molotch, H. (1994) The Compulsion of Proximity, in NowHere: Space, Time, and Modernity, Vol. (Eds, Friedland, R. and Boden, D.) University of California Press, Berkeley, CA, USA.

Burkhardt, M. E. (1994) Social interaction effects following a technological change: a longitudinal investigation. Academy of Management Journal, 37, 869898.

Burns, T. and Stalker, G. M. (1966) The Management of Innovation. Tavistock Publications, London. 
Carletta, J., Garrod, S. and Fraser-Krauss, H. (under revision) Communication and Placement of Authority in Workplace Groups --- The Consequences for Innovation. Small Group Research.

Carlisle, J. A. and Parker, R. C. (1989) Beyond negotiation: Redeeming customersupplier relationships. John Wiley \& Sons, Chichester, England.

Doherty-Sneddon, G., Anderson, A. H., O'Malley, C., Langton, S., Garrod, S. and Bruce, V. (1997) Face-to-Face and Video Mediated Communication: A Comparison of Dialogue Structure and Task Performance. Journal of Experimental Psychology: Applied, 3, 105-125.

Doyle, M. and Straus, D. (1976) How to make meetings work. Playboy Press, . Gattorna, J. L. and Walters, D. W. (1996) Managing the supply chain: A strategic perspective. Macmillan, London.

Greek, D. (1997) Delusion in good supply. Professional Engineer, 10, 28.

Gutek, B. A. (1997) Dyadic Interaction in Organizations, in Creating Tomorrow's Organizations: A Handbook for Future Research in Organizational Behavior, Vol. (Eds, Cooper, C. L. and Jackson, S. E.) Wiley, Chichester, pp. 139-155.

Guzzo, R. A. and Dickson, M. W. (1996) Teams in Organizations: Recent Research on Performance and Effectiveness. Annual Review of Psychology, 47, 307-338.

Jackson, B. B. (1985) Building customer relationships that last. Harvard Business Review, 63, 120-128.

Lipnack, J. and Stamps, J. (1997) Virtual Teams: Reaching across space, time, and organizations with technology. John Wiley, NY.

Martin, J. (1997) Part design comes together on the net. Mechanical engineering, June, 76-78.

Olson, J. S., Olson, G. M. and Meader, D. K. (1995) What mix of video and audio is useful for small groups doing remote real-time design work?, ACM, Denver, Colorado, USA, pp. 362-368.

Prokesch, S. E. (1997) Unleashing the power of learning: An interview with British Petroleum's John Browne. Harvard Business Review, September-October, 147168.

Sellen, A. J. (1995) Remote Conversations: The Effects of Mediating Talk with Technology. Human-Computer Interaction, 10, 401-444.

Silver, S. D., Cohen, B. P. and Crutchfield, J. H. (1994) Status differentiation and information exchange in face-to-face and computer-mediated idea generation. Social Psychology Quarterly, 57, 108-123.

Weldon, E. and Weingart, L. R. (1993) Group goals and group performance. British Journal of Social Psychology, 32, 307-334.

West, M. A. (1996) Reflexivity and Work Group Effectiveness: A Conceptual Integration, in The Handbook of Work Group Psychology, Vol. (Ed, West, M. A.) John Wiley.

\section{BIOGRAPHY}

The Human Communication Research Centre is an interdisciplinary research centre which includes staff from the Universities of Edinburgh and Glasgow. 
Professor A. Anderson heads their Multimedia Communications Group. Dr. J. Carletta and Ms. R. McEwan are research staff with backgrounds in computational linguistics and psychology, respectively. This work was funded by a grant from the Innovation Programme of the Economic and Social Research Council (UK). We would like to acknowledge TEAM, project AC070 of the European Commission ACTS Programme, for allowing us to record their virtual team trials and J. Bal and A. May for assistance with data collection. 